\title{
AS PRÁTICAS DE CURA DAS BENZEDEIRAS DA AMAZÔNIA PARAENSE: SABERES, IDENTIDADES E LUGARES DE GÊNEROS
}

\author{
THE POPULAR HEALING PRACTICES OF PARÁ AMAZON REGION: KNOWLEDGE, IDENTITIES, AND PLACES \\ OF GENDER
}

\section{RESUMO}

Este trabalho objetiva promover o resgate da memória de benzedeiras da comunidade de Taquandeua, situada no município de Bragança/PA. Busca-se encontrar quais posições são assumidas por elas, e qual é o papel que desempenham na região, motivadas pelos discursos que tomam seus corpos dentro do ofício da cura espiritual e biológica, possibilitando uma maior visibilidade ao processo de construção de ser mulher - conforme afirma Beauvoir (2019, vol. 2), tornar-se mulher é um processo -, baseada nas experiências de reza junto ao seu coletivo, que podem ou não ser membros da comunidade. Acredita-se que é nos arranjos da vida cotidiana que elas tecem suas próprias histórias, sustentadas na simbiose de corpo, na voz, nas orações, nos gestos e nas ações, ao produzir formas subjetivas de ser e estar no espaço social, e reproduzir efeitos para além dos prestígios da reza e práticas de cura.

Palavras-chave: Memória. Reza. Subjetividade. Gênero.

\begin{abstract}
This work aims to promote the memory recovery of healers from the community of Taquandeua, located in the municipality of Bragança / PA. It seeks to find out what positions they assume, and what role they play in the region, motivated by the speeches that take their bodies within the craft of spiritual and biological healing, allowing greater visibility to the process of building a woman - as says Beauvoir (2019, vol. 2), becoming a woman is a process - based on the experiences of praying with her group, who may or may not be members of the community. It is believed that it is in the arrangements of everyday life that they weave their own stories, based on the symbiosis of the body, in the voice, in prayers, gestures and actions, while producing subjective forms of being and being in the social space, and reproducing effects beyond the prestige of prayer and healing practices
\end{abstract}

Keywords: Memory. Pray. Subjectivity. Genre.

Nadson Fernando Nunes da Silva

UFPA. Email: nadsonfernando14@gmail.com

Norma Cristina Vieira

UFPA. Email: normacosta@ufpa.br

Marcelo do Vale Oliveira

UFPA. Email: marcelomvo@ufpa.br 


\section{Introdução}

Este estudo objetiva investigar, a partir do resgate da memória de duas benzedeiras ${ }^{1}$ da comunidade de Taquandeua, situada na Zona Rural do município de Bragança, na Amazônia Paraense. Os espaços de construção e de afirmação da mulher, no ofício da cura espiritual, surgem como marcadores de uma dada feminilidade.

Para descrever como ocorrem as reproduções e afirmações dos espaços de construção dos gêneros, atentamo-nos aos elementos que influenciam determinadas significações, que estão presentes nas posturas, nas orações, nos gestos, nas ações, e nos discursos nos quais entendemos que estes "[...] são indicadores de consumo e de forças [...]", e que "[...] são nas práticas do cotidiano que se apoiam numa problemática do enunciado" (Certeau, 1998: 103). Sendo assim, os discursos tornam-se elementoschaves para a análise dessas construções das benzedeiras, pois, a partir desses, buscamos suscitar diferentes perspectivas e análises, nos aproximando da memória individual, e coletiva, como figura metodológica que consiste em tratar fatos sociais, estruturados em suas hierarquias e classificações, reforçando sentimentos de pertencimento em múltiplos espaços sociais e culturais (Pollak, 1989).

Dentre os diversos campos que compõem o Discurso, essas mulheres apropriam-se de conhecimentos e saberes milenares, por meio de ensinamentos que perpassam gerações que possuem o dom da cura espiritual, cujas práticas da religiosidade tornam-se referências vivas de um processo de aprendizado que se produz através de conjuntos comunitários. Por estarem cotidianamente envolvidas no ato da cura e dos modos de se afirmarem como mulheres que produzem esses ensinamentos, as benzedeiras manifestam-se através das preces, dos gestos e das orações, dando significado às suas ações, a exemplo práticas de ensino.

Tais aprendizados de cura funcionam como exercício de formação humana, e a eles estão agregados um conjunto de saberes e habilidades que auxiliam o sujeito a lidar com a dor espiritual e física do outro, a partir de um cruzamento entre conhecimentos herdados de e aprendidos por intermédio de uma benzedeira mais experiente. Estes processos são essenciais para que se atinja a compreensão de que os espaços de cura e espiritualidade marcam, também, o lugar da educação, dos modos de ensinar e de se colocar-se dentro de uma comunidade tradicional como benzedeira.

O que evidencia as diversas relações em que o indivíduo constrói significações, e se forma como ser significante, e incorpora às suas ações, em movimento de totalizações abertas, sendo revelado por perspectivas, que inserido num cenário de múltiplas singularidades se entrecruzam com suas histórias e a dos outros, sendo produto e produtor, simultaneamente (Maheirie, 2002).

São essas singularidades que fazem emergir, sobre os fluxos da memória e do corpo, as conexões comunitárias entre pesquisa e pesquisador, os quais se deslocam sobre as vivências conjuntas de espaços, modos de vida e de aproximações humanas,

1 Profissão também conhecida em muitas comunidades da Amazônia como rezadeira. 
agindo não só na relação entre indivíduos, mas também entre comunidades. Assim, a pesquisa se estende para além de dois corpos, se fazendo por muitos outros, que se mostram conectados entre lances de olhares, no sentir/ver o universo paralelo de mundos distintos.

Metodologicamente, o trabalho é uma pesquisa qualitativa com participação direta no lugar em que os fenômenos estudados ocorrem, o que faz com que concebamos a forte influência exercida pelo contexto, traçada nas circunstâncias particulares nas quais determinado objeto se insere. As pessoas, os gestos, as palavras devem ser referenciadas ao contexto do qual fazem parte (Ludke \& André, 1986).

A pesquisa, ainda, é do tipo etnográfica, por se pautar nas vivências das benzedeiras, e pela maneira como são descritos os elementos dessa cultura, a exemplo das crenças, dos comportamentos e dos valores (Gil, 2002).

Para a coleta de dados, foram utilizadas entrevistas e experiências de corpo², os quais permitiram que fossem transpassados outros corpos (corpo sagrado), mergulhando por seus universos. As entrevistas ocorreram no espaço de convivência social e cultural de duas benzedeiras, uma com 54 anos, que chamaremos, pelo codinome, Rosa, e a outra com 36 anos, que chamaremos Margarida. Ambas são moradoras da comunidade rural de Taquandeua, localizada a $12 \mathrm{Km}$ da sede do município de Bragança/PA, no km o6 da Rodovia Bragança - Viseu, à margem direita do Rio Caeté. A experimentação, então, contou com um diário de campo como ferramenta subsidiária de análises. O período de coleta de dados ocorreu de março de 2018 a abril de 2019 .

O resgate da memória das entrevistadas foi um elemento fundamental para o entendimento da construção do ofício de cura praticado por estas mulheres, pois a memória é fruto das lembranças. De acordo com Sá (2007), não se resume apenas a uma reprodução de experiências passadas, mas, sim, é uma construção que se faz a partir da realidade presente e com o apoio de recursos proporcionados em um processo sócio-cultural.

As narrativas memoriais das mulheres, bem como as imagens fotográficas, a observação e os outros instrumentos de coleta utilizados em campo, possibilitaram embasamento para o entendimento do tema proposto, traçando um olhar para a compreensão de gestos, atitudes e posturas assumidos por e para elas, e ainda as relações de poder, os conflitos e as resistências presentes no ofício de cura.

\footnotetext{
2 A pesquisa é um exercício que acontece por um processo de ligação, interação e encontros, que, no cruzamento entre corpo e saberes, manifesta-se por uma incorporação, composta por fragmentos corporais que aproximam a pesquisa do pesquisador, a partir de um ato experiemental de si e do outro, os quais se deslocam por aberturas e também por entrega a um lugar (des)conhecido que se pretende, enquanto pesquisador (a), adentrar, deixando-se ser habitado por vozes, fluxos, forças e significações. Requer uma atitude (des)pretenciosa na medida em que nos tornamos liames entre conhecimento, espaço, e movimentos de uma nova língua; que não é nossa, mas que buscamos por elas sentir, permitindo que as aberturas conduzam as passagens, causando fissuras ao corpo do(a) pesquisador(a): aos seus olhos, para se fazer ver; aos seus ouvidos, para se fazer escutar; à sua percepção, para se fazer sentir; e ao seu corpo, para se fazer conectar (Rosa, 2009).
} 


\section{Mulheres que curam: guardiãs do conhecimento}

No Brasil Colônia acreditava-se na existência de um círculo vicioso que submetia as mulheres à influência cósmica, ligando-as aos mistérios da natureza. Era preciso ser filha, mulher, e mãe, para completar o ciclo natural (Del Priori, 2004).

Essa ligação, que aparece como marca de uma feminilidade, se estende para além de seus espaços de convivências, conectando dons à necessidade de equilíbrio do corpo e do espirito, abarcando o outro, que é próximo, comunitário, e que, caracterizado a partir da relação cliente/benzedor, exerce um papel de intermediação com o sagrado pela qual se tenta obter a cura. E essa intervenção terapêutica tem como processo principal o uso de preces (Quintana, 1999).

Entre preces e orações, ecoam saberes divinos, que são transmitidos através do contato com o sagrado, conduzidos no corpo e para o corpo, movidos por relações de domínios, proporcionando um alívio espiritual, que é mantido por essas mulheres como sua principal forma de existência. Sua força e habilidade de cura não são medidas por idade; jovens e idosas seguem o mesmo caminho e se misturam no ofício da reza.

As diferenças assentadas para homens e para mulheres, que praticam a cura, variam nas diferentes regiões do Brasil. No entanto, compreendemos que, culturalmente, os homens dominam a produção do que é sagrado, que é medida pelas marcas de corpo, força, hormônios e órgãos sexuais, o que faz com que essa dominação se estabeleça em diversos discursos, sociedades, e práticas religiosas (Nunes, 2005). Nos permitindo pensar como Loyola (1984), isto é, concordar com o fato de que, de acordo com as regiões e estruturas culturais, os homens, dentro do contexto de cura, são denominados como curadores, e não como rezadores, devido à diferença que se estabelece entre os agentes detentores do saber. Ainda para Loyola (1984), as benzedeiras geralmente estão aptas a dar bênçãos e a rezar para curar as doenças, enquanto a imagem que se tem do curador aparece com uma capacidade que vai além das praticas de rezar. Ele consegue entrar em contato com forças superiores, faz uso de trajes especiais, de orações e de implementos religiosos.

Características advindas das relações de poder mostram-se presentes no alívio do corpo humano. Acerca dessa questão, Louro (2003) traz essas relações como modos, compreendidas fora de suas construções pessoais, apontadas nos arranjos sociais, na História, nas condições de acesso aos recursos da sociedade, nas formas de representação, passando por diferentes e variados espaços.

Jovem ou idosa, a mulher segue o ofício que lhes foi destinado, fazendose presente por entre as dobras do corpo, entrelaçando ações à formas gestuais, rebatendo a libertação do outro, direcionando novos caminhos, sob a incumbência de um saber prático, uma herança de valores e domínios que, arraigados dentro do ofício dessas mulheres, recebem pontuações da não originalidade, por serem de um gênero visto, religiosa e culturalmente, inferior ao outro, que se apresenta no 
masculino (Santos, 2009). A contribuição das diferenças para as teorias de gênero dentro dos espaços de cura pode ser:

"Compreendida nas concretas relações sociais de poder, que se estruturam na realidade relacional dos seres humanos, resulta em processos de superação da concepção que isola a mulher, ou o homem, como categoria específica, e exige que a relação mesma entre homens e mulheres, mulheres e mulheres, e homens e homens, seja significativa, identificada sob estruturas de poder e controle imbricadas nas relações e seu respectivo reflexo na produção e reprodução do saber" (Sampaio, 2015:47).

A diversidade dessas mulheres, segundo Nunes (2015: 16), "desaparece diluída em um imaginário social que lhes atribui características comuns e que, assim agindo, as toma por um grupo homogêneo". Toda a análise da condição social e/ou religiosa das mulheres tem de levar da realidade em consideração, sob pena de distorcê-la, reproduzindo formas de ser mulher dentro desses espaços de cura e libertação. É aqui que elas se deixam escapar mostrando-se, para além de tais propriedades, como a "boa dona de casa", que cuida dos filhos, dos netos e dos maridos, regando suas próprias ervas, sustento de suas crenças.

Aqui, mulheres incorporam os desejos do divino, que transcorrem as veias espirituais, transcendendo por suas memórias o autoconhecimento manifestado na prática do tempo, que advém de outros lugares, de experiências regadas no benzido e no ofício da cura. Carregadas por distintas definições, encarregadas de responderem a partir do lugar de benzedeira. Elas representam formas de ser uma mulher que cura, pensada e refletida por uma categoria destinada pelo campo biológico. Tilly (1994) compreende que elas existem fora de suas matrizes compondo espaços sociais, incluindo pessoas de diferentes idades ao gênero feminino. Suas vidas são modeladas por diferentes regras sociais e costumes, em um meio no qual se configuram crenças e opiniões decorrentes de estruturas de poder.

A saber, as representações que as coligiram atravessam o tempo e estabelecem o pensamento simbólico da diferença entre os gêneros: a mãe, a esposa dedicada, a "rainha do lar", uma mulher sublimada; seu contraponto, a Eva, era debochada, sexual, constituía a vergonha da sociedade. Aos homens, o espaço público, político, com centralidade do poder, às mulheres, o privado é seu coração, o santuário do lar (Strey et. al, 2004). Por conseguinte, a mulher, ao pertencer a um legado configurado no decorrer dos tempos, é depositada na cópula da instauração da vida humana.

"Isolando os fins aos quais a natureza feminina deveria obedecer, tão somente a ideia de que o estatuto biológico, a mulher estava sujeita a naturalizar-se como terra fértil a ser fecundada, ligado a um outro, que é moral e metafísico: ser mãe, frágil e submissa, ter bons sentimentos" (Del Priori, 2004: 07). 
São sobre elas, erguidas entre o seio matriarcal, que recaem os modos de ser uma mulher femina e responsável por seu espaço familiar. Atributos que as aproximam dos feitos da reza, do sagrado, do zelo. Ao comporem a camada mais densa dos espaços sociais, Strey et. al (2004, p.16), argumentam que o corpo feminino "é o primeiro lugar da inscrição que a sociedade sempre leu, encarando a mulher a partir de suas produções, fechando-a na reprodução e na afetividade", destinando-as, assim, ao silêncio de outras formas de criação.

As categorias de gênero são compreendidas como aquilo que diferencia socialmente os sujeitos, considera os padrões atribuídos socialmente para homens e para mulheres, o que nos faz questionar como essas diferenças foram, a priori, estabelecidas (Lauretis, 1994). Portanto, o conceito de gênero, ao que conferem os argumentos da autora, não se restringe apenas aos papéis assumidos na sociedade, mas é caracterizado pelas relações de poder que estão implicadas e anexadas no interior de outras instâncias sociais, contribuindo para um novo ajuste de corpo, mente, e olhares.

Assim, o corpo feminino se estende para além do ser benzedeira, estabelece uma ligação social que as determina proprietárias de suas mães do corpo, devendo ter o cuidado de mantê-lo saudável, na virtualidade do ventre. O corpo masculino também tem suas mães, a diferença entre ambos está no fato de a mulher se constituir de um corpo oco, sugestivo ao útero, que copula, originando vidas, destinada à natureza feminina, a ser mulher, que também é mãe, que ao filho doa seu corpo, cria no seio, multiplica, construindo-se dentro e fora de suas ações, sustentada em suas crenças. Conforme citado em Motta-Maués e Villacorta (2008: 343) "Mulheres e homens são diferentes "por fora" e "por dentro". Uma das principais diferenças é que o homem é "inteiro", e a mulher não, o que está ligado à sua função reprodutora, pois significa que ela possui na sua "barriga" um lugar vago, ou seja, não ocupado por nenhum órgão, o que não acontece com o homem”.

Vale ressaltar que, ainda de acordo com Motta-Maués e Villacorta (2008), o termo "ventre" só é empregado para referir-se à mulher, pois os homens só possuem "barriga”. É no ventre que se localizam os órgãos reprodutores responsáveis pela gestação, constituindo, então, o "maquinismo" da mulher, também conhecido, na comunidade de Taquandeua, como mãe do corpo, que é vivo, nutrido, e significante para a nomenclatura feminina.

Os autores ainda indicam que a diferença entre homens e mulheres, pensada no corpo, transforma, na verdade, as mulheres, numa linguagem de sistemas simbólicos que tem sua correspondência plena nas práticas sociais, como é o caso de seu desempenho no ato da cura, em corpos vazios de outro qualquer sentido que não seja o da reprodução.

O período menstural, que é, basicamente, um processo de preparação para a fecundação em que a mulher passa pela ovulação e adentra em um período fértil, marca, no ofício espiritual, a elevação dos poderes de cura, visão e aproximação de entidades, fazendo com que elas sejam tidas como perigosas, desde o olhar ao toque, 
comprovando quão intimamente ligadas ao corpo e suas modulações as benzedeiras estão.

"Quando fico doente (período menstrual) quanto mais eu fazer remédio, mais curar os outros, melhor ainda, o poder fica mais forte, derrubo qualquer espirito eu". (Margarida, 2018).

Diante disso, percebemos que a mulher é sempre inserida num "lugar" de sujeição ao homem. Motta-Maués (1994: 113) afirma existir um perfil ambíguo, como fonte de vida, exercendo o papel de mãe, e de morte, enquanto ativadora de forças destruidoras e dona de um poder perigoso. Nesse contexto, dois elementos são de especial importância: os poderes perigosos atribuídos à mulher, a exemplo de veneno e panema ${ }^{3}$, e a reima 4 .

Para além da benzeção, elas são capazes de entrar em contato com espíritos, almas, santos/as, encantados, caruanas, índios e caboclos. Alcançam o todo, seus olhos são portas abertas para distintos universos, buscando equilíbrio. Silenciosas nos olhares, sussurram na calmaria, manifestando nas marcações do saber.

"Rezo mais em criancinha, às vezes gente grande também, tem vez que é pra peito aberto, espírito ruim, até gente morta eu vejo (...). 'Pra' costurar rasgado também eles vêm muito aqui, pra essas coisas a gente tem mais o jeito". (Rosa, 2018).

Idosos, crianças, homens e mulheres amparam-se nas boas ações das benzedeiras, que, na agilidade das mãos, leves e delicadas, trançam seus saberes no jogo do acolhimento, costuram almas feridas, deslizam seus dedos eomo tal qual agulhas, entrelaçando fios de cura, que, na magia de suas orações, cingem o corpo e a alma, fechando e afastando os males.

Elas, assim como outras pessoas, estão vulneráveis às enfermidades que podem acometer o corpo e a alma. São nessas ocasiões, entre dar e receber a cura, que surge a figura do homem, no retraimento do seu quarto, protegido por muitos santos, revestido no sagrado, transfigurado, fazendo com que, em momentos de agonia, ele não busque orações e proteção.-

"Sempre vou lá na casa do Zeca quando tô muito aperriada, ele me benze, afasta coisas do bicho que quer se pegar em mim (...) me dou bem com o benzimento dele (...) ele tem muito santo, tem todos os apreparos, num quartinho na casa dele". (Rosa, 2018).

3 Classificação dada, sobretudo, as mulheres quando estão menstruadas, grávidas e em outras circunstâncias.

4 Classificação dada a determinados alimentos tidos como "perigosos” para a saúde em certas situações. Exemplo: Os crustáceos e os moluscos, em geral, são tidos como "remosos” no pós-operatório de homens e de mulheres. 
"Não vou nessas daqui não, eu não tenho raiva não (...) Depois ficam só falando por trás, ainda mais essas que parece que faz coisas do bicho". (Rosa, 2018).

Ao identificar-se a si e ao seu grupo, como mulheres presentes no convívio comunitário, despindo seu corpo em uma manifestação de cura, Rosa expõe o gênero masculino como única fonte segura de curá-la, cabendo a ele recebê-la no acolhimento de seu espaço sacralizado, com alto poder perpetuado entre seus muitos santos, por causa da sua fidelidade no conhecimento espiritual, apontando as outras mulheres como não honestas, com menor capacidade.

"O homem é diferente da mulher, tem muita coisa que é diferente (...) sabe porquê? Porque ele pare primeiro que nós mulher, quando sai aquele leite branco (espermas). Muito depois que a gente vai botar pra fora a criança”. (Margarida, 2018).

Descendente de avós indígenas, Margarida reproduz o posicionamento colocado por Laraia (2001: 47), ao fazer referência à concepção dos índios Tupi, pois, para estes, "a criança depende exclusivamente do pai. Ela existe anteriormente como uma espécie de semente no interior do homem, muito tempo mesmo antes do ato sexual, que a transferirá para o ventre da mulher".

O mistério da maternidade, segundo Fares (2008: 318), figura entre os principais enigmas femininos:

"O ventre fecundado cresce, dele nasce um ser com todas as condições de vida, de algum modo relacionando-se com o brotar das plantas e com o desabrochar das flores. A mulher aproxima-se da natureza, repete o mesmo processo em qualquer lugar, por isso conhece melhor os seus segredos, não só o de profetizar, mas o de curar. O feminino associa-se a terra-mãe, que é ventre nutridor" (Fares, 2008: 318).

O homem também é tabernáculo existencial, é um corpo que produz, que lança, porém, não faz brotar, argumento pronunciado pelas mulheres.

"Muita das vez o homem não ganha mulher, sabe. Eu falo assim no meu caso né! Que homem não tem mais poder que a gente, porque realmente, trabalha as vezes só numa coisa e nós mulher trabalha várias coisas, entendeu? Ainda bota o filho pra fora né!" (Margarida, 2018).

Margarida indica as marcas que definem as diferenças na relação entre conhecimentos e poderes de homens e mulheres dentro do ofício espiritual da cura. 
Ao dizer que o "homem não ganha uma mulher", expõe que os muitos espaços nos quais eles transitam, seja no contexto espiritual ou conectadas ao lar, não envolvem diversas atividades diárias com a capacidade que elas têm de articular e completar os espaços assentados socialmente.

"Olha, eu tô aqui em casa, eu varro uma casa, eu lavo uma louça, né? Cuido dos meus filhos, lavo uma roupa, varro o meu quintal. Chega uma pessoa, eu converso, explico, benzo, se for pra fazer trabalho eu faço. Sobra tempo, ainda faço minha janta, eu tenho tempo pra tudo". (Margarida, 2018).

Em um repertório de ancestralidade e tradição, o corpo feminino, que se pronuncia nas benzedeiras de Taquandeua, por um lado retoma as práticas que subvertem a lógica da sociedade capitalista ao apresentarem-se como mulheres muito mais conectadas e sensíveis à natureza, às forças das águas, aos dons divinos e à medicina tradicional; por outro, uma mulher tal como a maioria, ela mostra, em seu discurso, o acúmulo de diferentes funções, da produção à reprodução, enraizada no saber fazer, preenchendo seu corpo de mulher dentro das estruturas, em boa medida, fixas, dos lugares de gênero, característica marcante das comunidades tradicionais da Amazônia.

\section{Espaço, existência e benzeção}

Para além do reportório simbólico que circunda as crenças das benzedeiras, o lar é o seu espaço de construção, assentado sobre o quintal, bem como lugar de convivência familiar, inserido como extensão de suas cozinhas, característico de comunidades rurais amazônidas, sintetiza seu pertencimento.

Observamos que essas mulheres se apropriam do quintal como espaços de existência. Segundo Del Priori (2004), além de servir para que seja feita a plantação de ervas para curas e práticas mágicas, constitui-se como peça fundamental para a economia familiar, pois é onde se concentram o plantio de subsistência, a criação doméstica e a cozinha. O quintal é o território prestigiado da cultura feminina, feita de empirismo, oralidade, e memória gestual. É por esse ambiente que elas se deixam mostrar, formando-os como lugar privilegiado de mulher, de oração, de preces, de encontros e de compromissos.

"Eu benzo aqui mesmo onde eu tô, no quintal (...), aí chega alguém pra benzer, vou ali, apanho uma rama, e já benzo. Sabe, né, a gente que é mulher é assim mesmo (...), hum, aqui eu faço de tudo, é pra filho, é pra neto... e ainda tenho que cuidar do meu velho, dia todo nisso (...). Sou quase o pai da casa”. (Rosa, 2018). 
Socialmente destinado ao feminino, com distintas formas de realizar as amarrações de cura, o quintal é parte fundamental para a produção de seus conhecimentos, funcionando como um instrumento de suas atividades que se estende do doméstico ao espiritual. Percebemos, em Rosa, a busca constante pelo equilíbrio entre benzer e dedicar-se à família; sua presença em todos os cômodos da casa é visível, cuida dos filhos, dos netos e do marido. Este, afastado das atividades por motivo de doença, aparece no conjunto social marcando o lugar da masculinidade.

Recaem sobre as mulheres a incumbência de dedicarem-se ao lar, à família e à reza, preparando o ambiente e a terra no cultivo da medicina tradicional, formulando chás, xaropes, banhos, e utilizando as plantas como principal método subsidiário nos rituais de cura e proteção.

\begin{abstract}
"Eu mesma planto os meus remédios, desde hortelãzinha, arruda, cravo-de- defunto, erva-cidreira (...) aí serve pra tudo, febre, rasgado, dor de cabeça, olhado de bicho, quebranto. Quando a pessoa não tem, eu dou pra levar e ir fazendo se precisar". (Rosa, 2018).
\end{abstract}

A força dessas mulheres está diretamente conectada às seivas que a natureza produz. Seus corpos funcionam como aberturas que comportam e capturam um conhecimento empírico na manipulação e produção do uso das plantas medicinais, que é fluido e perpassa gerações, reproduzindo, por meio de diálogos e práticas, o ensino de suas estruturas, fórmulas, combinações, e métodos adequados para que o uso de suas partes, a saber, as raízes: Gengibre, Patinxolim, Pripioca, raiz de açaí; as folhas: Alecrim, Arruda, Boldo, Angélica, Eucalipto, Hortelã, Hortelãzinha, Ervacidreira, Trevo-Roxo; os caules: Verônica; as sementes: Barbatimão, semente de Mamona; e os frutos e flores: Cabacinha, Andiroba, Cravo-de-defunto, Cravinho.

Assim, a medicina, dentro do oficio de cura, a partir do uso das estruturas botânicas, passa a ser considerada como fonte sacralizada, cabendo envolver diferentes sistemas de crenças, tendo as plantas como entes sagrados, mágicos, com poderes curativos, atribuídas a propriedades que vão além das classificações taxonômicas, das fórmulas químicas e das análises farmacológicas (Carvalho et.al, 2017).

Considerando que, ao decorrer de nossa existência, são construídos lugares e posições em que mulheres e homens devem assumir, biblicamente a mulher estava condenada, por definição, a pagar eternamente pelo erro de Eva, a primeira fêmea, que levou Adão ao pecado e tirou da humanidade futura a possibilidade de gozar da inocência paradisíaca. Já que a mulher partilhava da essência de Eva, tinha de ser permanentemente controlada, cabendo autoridade e superioridade ao masculino (Araújo, 2004).

Logo, essas benzedeiras desenvolvem-se como parte do corpo da comunidade, sendo mulheres que têm um dom divino de curar e de benzer, apreendido pela prática da observação de outras mulheres que também têm o mesmo dom. Nas 
palavras de Nascimento \& Ayala (2013), as benzedeiras, também conhecidas como benzadeiras, possuem uma importante função na parcela da sociedade que mantém usos e costumes tradicionais, estabelecendo relações com o sagrado.

Detentoras de um saber religioso, elas são capazes de, por meio das rezas e dos rituais, curar males e devolver o equilíbrio emocional e físico àqueles que as procuram. Essas mulheres, geralmente, são da mesma família e fazem parte de um círculo de hierarquia matriarcal. São respeitadas pela população por carregarem consigo os conhecimentos místicos de uma geração antiga e por seus domínios de cura, de ver além dos olhos, de contemplar.

Referindo-se à imagem que se tem dessas mulheres benzedeiras, na obra, $\mathrm{O}$ que é Benzeção, Oliveira (1985) diz que

\begin{abstract}
"Geralmente é a de que seja uma mulher casada, mãe de alguns filhos, pobre, que conheça rezas, ervas, massagens, cataplasmas, chás e simpatias, que tenha um quê de mistério, que lide com a magia, feitiçaria e bruxaria. E essa imagem corresponde àquilo que é a benzedeira. Ela é tudo isso e um pouco mais. Ela é uma cientista popular que possui uma maneira muito peculiar de curar: combina os místicos da religião e os truques da magia os conhecimentos da medicina popular" (Oliveira, 1985: 25).
\end{abstract}

Por uma troca de valores e conhecimentos, e por sentirem-se seguras com as ervas em mãos, as benzedeiras se tornam promissoras na confecção dos seus "canteiros", definido por elas como uma espécie de farmácia popular local, que, consequentemente, contribui para a cura de doenças dos comunitários.

Há uma intimidade entre as mulheres de Taquandeua na plantação de ervas e óleos. As benzedeiras chamam de "verdadeira mulher" quem dedica-se ao trabalho de plantar e colher seus próprios remédios. Essa relação é tida como feminina e exige dedicação e conhecimento.

"A mulher tem que saber plantar pelo menos um pé de mato, elas não moram em cima da pedra”. (Margarida, 2019).

A expressão "morar em cima da pedra", adotada por elas, remete à mulher preguiçosa, insensível, que não se dedica a manusear a terra para cultivar suas plantas, em função do cuidado e proteção com a família, com os filhos, e consigo mesma.

"Tem muita das vez que o homem planta, tem uns que planta, outros não (...) mais é mulher que planta mais". (Margarida, 2019).

Com "mulher que planta mais", ela quer dizer que, mesmo os homens realizando a cura por meio da reza, com o uso de plantas medicinais, não possuem 
a mesma capacidade e dedicação para plantar, cultivar, e cuidar, assinalando serem estas tarefas genuinamente femininas, em virtude da ligação existente entre natureza e mulher. Para tanto, honrando suas crendices, obedientes ao chamado espiritual e carnal ancorados nos aspectos sonoros, visuais, e gestuais, as benzedeiras recorrem, cotidianamente, ao conhecimento dos encantados, concebendo o bem-estar físico e espiritual.

\begin{abstract}
“Tem gente que chega aqui comigo precisando de uma reza, de dar um passo, de tirar um espírito, eu não me nego não, eu faço mesmo, eu gosto disso. Eu não cobro não (...) Deus não deixou reza vendida, deixou pra gente socorrer na hora que precisa". (Margarida, 2018).
\end{abstract}

O ofício da cura, aqui, não se manifesta como trabalho enquanto produção de riqueza, de acúmulo de capitais e lucro, mas elas buscam, em suas ações, demostrar dedicação e respeito ao que fazem. Justificam-se como ajudantes de Deus, escolhidas para levar o bem e a saúde a quem precisa, a partir da sabedoria e como proteção do ser. Em trabalho similar, realizado por Moura (2011:347), elas cultivam a ideia de que "deve-se dar de graça o que de graça se recebe, aceitam apenas agrados, tais como gêneros alimentícios, tidos como gestos de gratidão pelo bem que se fez. Aceitar pagamento é renegar o dom que foi dado, ou seja, a graça divina". As benzedeiras enfrentam diversas enfermidades e provações, a serem firmadas dentro daquilo que elas acreditam, e muitas vezes essas situações se apresentam da manifestação de vultos e vozes sussurradas no sossego de seus olhares.

Em comunidades rurais, nos deparamos com mulheres condutoras do lar, pouco escolarizadas, que nos remetem, à primeira vista, à figura de mulher submissa e subjugada pelas normas estruturantes de gênero, mas na reza, elas foram capazes de recriar nesses corpos marcas de feminilidade, sobretudo pelo ofício que receberam de outras mulheres como mediadoras de um dom divino.

"No meu caso eu faço de tudo, eu incorporo, faço terreiro, canto, derrubo espírito, tiro feitiço(...) tenho minhas vestes, uso meus colares, faço defumação, faço muitas coisas, sabe! Igual muito homem faz por ai!". (Margarida, 2019).

As práticas de Margarida invadem os espaços declarados masculinos. Por sua capacidade de transitar entre os caminhos da benzedura e da umbanda ${ }^{5}$,

5 A umbanda é compreendida como uma religião brasileira, de caráter sincrético e socialmente dialético, fluida e permeável às influências históricas. A umbanda comunica-se, sobretudo, através de manifestações corporais, gestuais, vivenciais e artísticas. Apresenta-se em ações e mensagens embaladas pela corporalidade da música, da dança e pelo uso recorrente de metáforas poéticas que impactam vivencialmente os participantes, manifestando-se pelo encadeamento dos seus símbolos, que se revelam inteligíveis à medida que o interlocutor progressivamente se afina com a sua linguagem e sistema simbólico e passa a ser capaz de "senti-los" (Pagliuso; Bairrão, 2010, p.198). 
compreendemos como um novo repertório de mulher e que se conjugam a atos que equivalem, socialmente, à negação e à maldade, classificando-os como feitiçaria.

"Logo quando comecei a trabalhar, eles (encantados) diziam assim: olha, ela não é feiticeira, ela somente é uma curandeira, porque feiticeira é quem não tem devoção a Deus, não tem devoção a ninguém, é só de fazer maldade, e eu nunca fiz, isso, não, nem experimentei e nem quero". (Margarida, 2019).

Em determinas comunidades, as benzedeiras são tidas como feiticeiras por ocuparem um lugar central. As mulheres são julgadas por dominarem os instrumentos de poder e prestígio, exercendo autoridade, assumindo comportamentos de domínio nos espaços considerados proibidos para elas (Maluf, 1992).

Podemos perceber que Margarida constitui-se através dessas expectativas, despindo-se da norma, recriando um corpo-mulher que não se mostra protagonista, reinventando outras visões para produzir-se como mulher de cura, amarrada aos laços comunitários, mergulhada sob os mistérios de santos, representa incorporação e superação de medos. Na busca pelo equilíbrio espiritual, as benzedeiras manifestamse através de suas ações, alegando os olhares que marcam as virtudes femininas, ancoradas na sociedade.

"No início, assim que comecei a benzer, eu tinha muita vergonha, eu não queria fazer isso, mais eu tenho dó das criancinhas que choram com qualquer dor que seja, não gosto de ver criança sofrendo, a gente que é mãe já sabe né?" (Rosa, 2018).

Sucede na atitude de Rosa um clamor por se fazer presente ao bem do próximo, manifestado na ajuda às crianças, refletindo, em seu ser, os sentimentos da benzedeira que é mãe, que põe no colo, acaricia, acalma com palavras doces e gentis. É a maternidade que se justifica para a ação das orações e das preces, levada numa mescla de sentimentos e proteção, reproduzindo comportamentos da mãe, mulher mais velha, que revive, através da recordação, as emoções da gravidez, do parto, e do cuidar (Correia, 1998). O ofício da cura se mistura com a domesticidade e torna-se uma extensão da benzedeira.

Às vezes eu não preciso de nada pra fazer a reza, sabe? basta eu colocar a minha mão na parte que tá com a dor e na doença, que logo já vai abrandando, é assim que é, chega a palma da mão fica vermelha. Tem vez que, quando é muito forte, aparece um sinal, assim, nelas, como uma furada de prego, igual aos furos de Jesus, tu sabe como é, né? (Margarida, 2018, grifos nossos). 
São as mesmas mãos que, envoltas em um mistério de ordem divina, se deixam levar para além de suas consagrações, visibilizando as marcas de seus poderes de cura, que, pressionadas sobre a dor, aliviam o martírio. Senhoras de seus conhecimentos, destinadas aos seus espaços de construção, perpetuam fielmente os fazeres de seus ofícios, são dedicadas e habilidosas, apreciando o cuidar, o plantar, e o reestruturar, buscando, no silêncio da alma, transportar-se. Sendo o ritual da benzeção rico em simbologia, Moura (2011) argumenta que todos os elementos são partes constitutivas de um mesmo espetáculo: o local em que se benze, os objetos, as orações, e a expressão corporal. Unificados, eles garantem a crença na eficácia do ritual de benzeção.

\begin{abstract}
"Eu sempre tive isso desde criança (...) mas eu não sabia trabalhar, eu sofria muito, adoentada. Sempre fui doente, minha vó contava. Depois que eu tive o meu primeiro filho, eles (encantados) aperriaram muito. Comecei a ver mais forte, eles vinham falar comigo, era hora já (...) num trespasso, assim, igual dormente, me levaram pro fundo, eu vi de tudo lá, aprendi muita coisa do bem" (Rosa, 2018).
\end{abstract}

Para alcançar a ordem espiritual da cura, as benzedeiras realizam um ritual de passagem, conectando-se, inteiramente, aos seus dons, a partir do momento em que seus corpos atravessam a fase de menina para mulher adulta e, posteriormente, mãe. Naturalmente, ao fecundarem-se de vida, retomam seus corpos em um chamado para o fundo, envolvidas no encantamento do novo, repousando sobre os saberes de curar, benzer, possuir, e fazer-se presente ao perfil dessa feminilidade que é amarrada às necessidades do outro.

\title{
Considerações finais
}

Pensar o fenômeno da benzeção é problematizar uma manifestação de crença popular, que transversaliza as benzedeiras conectadas aos rituais de cura. Suas práticas se fazem presentes no cotidiano comunitário, não somente de forma institucionalizada, mas sob várias matrizes, na forma de esperança, atribuindo novos significados à vida, ao sofrimento, e à existência de um universo paralelo.

O ser mulher, e suas representações na comunidade estudada, aparece na habilidade de lidar e de se conectar com a natureza e seus espíritos, no sentido de produzir e gerar elementos como remédios, alimentos, benção e cura. Entendemos que as práticas realizadas por mulheres não são regras pontuadas, no entanto, compreendemos que somos, enquanto sujeitos, corpos modelados por uma sociedade patriarcal, de gestos e ações hierarquizadas, o que leva homens e mulheres a reproduzirem atividades culturalmente impostas, que são refletidas nas estruturas categóricas de gênero. Isso evidencia, dentro da pesquisa, quando as narrativas 
dessas mulheres são trazidas a partir de seus quintais, suas cozinhas, seus lares e modos de cuidar, sendo esses lugares socialmente locados para caber o corpo e a feminilidade da mulher.

Assim, concebemos que as diferenças entre homens e mulheres, no âmbito da cura espiritual, se desloca constantemente em virtude de uma relação de poder e dominação introduzida e desempenhadas nas articulações sociais e culturais, caracterizada pelos espaços de convivência, compromisso e santificação com o sagrado a partir do que se pode alcançar para o que culturalmente "é de homem" ou "de mulher".

\section{Referências}

ARAÚJO, Emanuel. (2004). "A arte da sedução: Sexualidade feminina na colônia”. In: PRIORI, Mary Del et al. História das mulheres no Brasil. $7^{\text {a }}$ ed. São Paulo: Contexto, p. $01-108$.

BEAUVOIR, Simone de. (2019). O segundo sexo: a experiência vivida. Tradução de Sérgio Milliet. $5^{\mathrm{a}}$ edição. Rio de Janeiro: Nova Fronteira.

BUSIN, Valéria Melki. (2011). Religião, sexualidades e gênero. Revista: Rever, Ano 11, No 01, P.106-124.

CARVALHO, Sérgio Zanata; BONINI, Luci Mendes de Melo; Almeida-Scabbia, Renata Jimenes. (2017). Etnoconhecimento de plantas de uso medicinal por benzedeiras/ benzedores e rezadeiras/rezadores de Anhembi e Mogi das Cruzes - SP. Revista Eletrônica Correlatio, v. 16, n. 2.

CERTEAU, Michel de. (1998). A arte de fazer invenção do cotidiano. Ed. Petrópolis: Vozes.

CORREIA, Maria de Jesus. (1998). Sobre a maternidade. Análise Psicológica, v. 3, p.365371.

DEL PRIORI, Mary. (2004). "História das mulheres no Brasil”. In: PRIORI M. D. Magia e medicina na colônia: $O$ corpo feminino. $7^{\mathrm{a}}$ ed. São Paulo: Contexto, p. o1- 63.

FARES. J. A. (2008). "Gênero e Pajelança na Amazônia - A Matintaperera no imaginário Amazônico”. In: MAUÉS. R. H; VILLACORTA, G. M. Pajelança e Religiões Africanas na Amazônia. Belém- EDUFPA, p. 13-361.

GIL, Antônio Carlos. (2002). Como elaborar projetos de pesquisa. $4^{\underline{a}}$ ed. São Paulo: Atlas. 
GOHN, Maria da Glória. (2014). Educação Não Formal, Aprendizagens e Saberes em Processos Participativos. Investigar em Educação - II a Série, Número 1.

LARAIA, Roque de Barros. (2001). Cultura: Um conceito antropológico. Jorge Zahar Editor, Rio de Janeiro, 14 ${ }^{\mathrm{a}}$ edição, p. 07 - 113.

LAURETIS, Teresa de. (1994). La tecnología del género. p.207 - 241.

LOURO, Guacira Lopes. (2003). Gênero, sexualidade e educação: Uma perspectiva pós-estruturalista. 6a ed. Petrópolis, RJ, Vozes.

LOYOLA, Maria Andreia. (1984). Médicos e curandeiros: conflito social e saúde. Coleção Corpo e Alma do Brasil, São Paulo: Difel.

LÜDKE, Menga; ANDRÉ, Marli E. D. (1986). Pesquisa em educação: abordagens qualitativas. São Paulo: Editora Pedagógica e Universitária, ano 5, n. 31.

MAHEIRIE, Kátia. (2002). Constituição do sujeito, subjetividade e identidade. Interações, vol. 7, n.13, p. 31-44.

MALUF, Sônia Weidner. (1992). Bruxas e Bruxaria na Lagoa da Conceição. Revista Crítica de Ciências Sociais, ${ }^{\circ}$ 34, p.99-112.

MOTTA-MAUÉS, Maria Angélica; VILLACORTA, Gisele Macambira. (2008). "Gênero e Pajelança na Amazônia- Matintapereras e pajés: gênero, corpo e cura na pajelança Amazônica”. In: MAUÉS. R. H; VILLACORTA, G. M. Pajelança e Religiões Africanas na Amazônia. Belém- EDUFPA, p. 13-361.

MOTTA-MAUÉS, Maria Angélica. (1994). "LUGAR DE MULHER: Representações sobre os Sexos e Práticas Médicas na Amazônia (Itapuá/Pará)” In: Alves, Paulo Cesar (org.). Saúde e doença: um olhar antropológico. Rio de Janeiro: Editora FIOCRUZ, p. 09-167.

MOURA, Elen Cristina Dias de. (2011). Eu te benzo, eu te livro, eu te curo: nas teias do ritual de benzeção. Mneme - revista de humanidades, 11, p. 340-369.

NASCIMENTO, Daniele Gomes; AYALA, Maria Ignez Novais. (2013). As práticas orais das rezadeiras: um patrimônio imaterial. Dossiê: Voz e Interculturalidade (UFRGS) Nau Literária: critica e teoria de literaturas, v: 09, n.1.

NUNES, Maria José Rosado. (2005). Gênero e religião. Dossiê: Pontifícia Universidade Católica de São Paulo. Estudos Feministas, Florianópolis, p. 363-365. 
NUNES, Maria José Rosado. (2015). "Gênero e experiência religiosa das mulheres. Corporeidade, etnia e masculinidade: Reflexões do I Congresso Latino-Americano de Gênero e Religião”. In: MUSSKOPF A. S.; STROHER M. J. São Leopoldo: Sinodal, p. 05-156.

OLIVEIRA, Elda Rizzo de. (1985). O que é Benzeção. 2 a ed. São Paulo: Editora brasiliense.

PAGLIUSO, Ligia.; BAIRRÃO, José Francisco Miguel H. (2010). Luz no caminho: corpo, gesto e ato na umbanda. Rev. Afro-Ásia, Bhaia, p. 195-225.

POLLAK, Michael. (1989). Memória, Esquecimento e Silêncio. Estudos Históricos. Rio de Janeiro, v. 2. n. 3, p. $03-15$.

QUINTANA. Alberto Manuel. (1999). A ciência da benzedura: mau-olhado, simpatias e uma pitada de psicanálise. São Paulo - Bauru: EDUSC, p. o9-210.

ROSA, Rogério Machado. Corpos híbridos na docência: experiências, narrativas de si e (des)construção das amabilidades no magistério. Dissertação de mestrado, Universidade Federal de Santa Catarina-UDESC, Florianópolis. P. 11-111.

SÁ, Celso Pereira de. (2007). Sobre o Campo de Estudo da Memória Social: Uma Perspectiva Psicossocial. Psicologia: Reflexão e Crítica, 20 (2); Rio de Janeiro, p. 290- 295.

SAMPAIO. Tânia Maria Vieira. (2015). Gênero e religião no espaço da produção do conhecimento: Corporeidade sob o prisma do gênero, da etnia e classe Corporeidade, etnia e masculinidade: Reflexões do I Congresso Latino-Americano de Gênero e Religião. São Leopoldo: Sinodal, p. 05-156.

SANTOS, Francimário Vito dos. (2009). O ofício das rezadeiras como patrimônio cultural: religiosidade e saberes de cura em Cruzeta na região do Seridó Potiguar. Revista CPC, São Paulo, n. 8, p. 6-35.

STREY, MarleneNeves. (2004). Gênero e cultura: questões contemporâneas. EDIPUCRS - Porto Alegre, p. o7-173.

TILLY, Louise A. (1994). Gênero, história das mulheres e História social. Cadernos Pagu, v. 3, p. 29-62.

WOODHEAD, Linda. (2013). As diferenças de gênero na prática e no significado da religião. Estud. sociol. Araraquara v.18 n.34 p.77-10o.

Recebido em 19/12/2019.

Aceito em 24/05/2020. 